\title{
Promotion, prevention and protection: interventions at the population- and community-levels for mental, neurological and substance use disorders in low- and middle-income countries
}

Inge Petersen ${ }^{1 *}$, Sara Evans-Lacko ${ }^{2}$, Maya Semrau $^{2}$, Margaret M. Barry ${ }^{3}$, Dan Chisholm ${ }^{4}$, Petra Gronholm², Catherine O. Egbe ${ }^{5,6}$ and Graham Thornicroft ${ }^{2}$

\begin{abstract}
Background: In addition to services within the health system, interventions at the population and community levels are also important for the promotion of mental health, primary prevention of mental, neurological and substance use (MNS) disorders, identification and case detection of MNS disorders; and to a lesser degree treatment, care and rehabilitation. This study aims to identify "best practice" and "good practice" interventions that can feasibly be delivered at these population- and community-levels in low- and middle-income countries (LMICs), to aid the identification of resource efficiencies and allocation in LMICs.

Methods: A narrative review was conducted given the wide range of relevant interventions. Expert consensus was used to identify "best practice" at the population-level on the basis of existing quasi-experimental natural experiments and cost effectiveness, with small scale emerging and promising evidence comprising "good practice". At the community-level, using expert consensus, the ACE (Assessing Cost-Effectiveness in Prevention Project) grading system was used to differentiate "best practice" interventions with sufficient evidence from "good practice" interventions with limited but promising evidence.

Results: At the population-level, laws and regulations to control alcohol demand and restrict access to lethal means of suicide were considered "best practice". Child protection laws, improved control of neurocysticercosis and mass awareness campaigns were identified as "good practice". At the community level, socio-emotional learning programmes in schools and parenting programmes during infancy were identified as "best practice". The following were all identified as "good practice": Integrating mental health promotion strategies into workplace occupational health and safety policies; mental health information and awareness programmes as well as detection of MNS disorders in schools; early child enrichment/preschool educational programs and parenting programs for children aged 2-14 years; gender equity and/or economic empowerment programs for vulnerable groups; training of gatekeepers to identify people with MNS disorders in the community; and training non-specialist community members at a neighbourhood level to assist with community-based support and rehabilitation of people with mental disorders.
\end{abstract}

\footnotetext{
*Correspondence: peterseni@ukzn.ac.za

${ }^{1}$ Centre for Rural Health, School of Nursing and Public Health and School

of Applied Human Sciences, University of KwaZulu Natal, Durban, South

Africa

Full list of author information is available at the end of the article
} 
Conclusion: Interventions provided at the population- and community-levels have an important role to play in promoting mental health, preventing the onset, and protecting those with MNS disorders. The importance of intersectoral engagement and the need for further research on interventions at these levels in LMICs is highlighted.

Keywords: Mental health, Community, Population-level, Low- and middle-income countries

\section{Background}

Over two thirds of people with mental, neurological and substance use (MNS) disorders do not receive the care they need worldwide [1]. This is particularly acute in lowand middle-income countries (LMICs), which is home to three-quarters of the global burden of disease attributable to mental and neurological disorders [2].

In addition to strengthening services for mental health care provided by the health care system, for example, through programmes such as the Mental Health Gap Action Programme (mhGAP) [3, 4]; interventions at the population and community levels that promote mental health; prevent the development of MNS disorders and protect people with MNS disorders are also important. At the population-level, mechanisms for the delivery of these interventions include legislation, regulations, and public information campaigns. At the community level, these interventions are best delivered at schools, workplaces, and in neighbourhoods/community groups, requiring a settingbased approach.

In pursuit of reducing the burden of mental disorders in LMICs, identifying interventions that can be effectively and feasibly delivered at these levels is helpful to decision-makers as it highlights where resources should be allocated, besides in the health care sector (e.g. to schools or non-governmental organizations in the community). It also enables potential opportunities, synergies and efficiencies to be identified across multiple sectors.

This paper provides an overview of the evidence for interventions at the population- and communitylevels in LMICs along the continuum of care from interventions that promote positive mental health, and primary preventative interventions which strive to prevent the onset of MNS disorders; through to identification and case detection; as well as treatment, care and rehabilitation. The evidence presented for each level is structured around these core elements of the continuum of care. The review was informed by the chapter on population and community 'platforms' or levels of care in the mental health volume of Disease Control Priorities (third edition) [5] as well as the mental health promotion and prevention aspects of the World Health Organization Regional framework to scale up action on mental health in the Eastern Mediterranean Region [6].

\section{Methods}

\section{Population level interventions}

Population level interventions are rarely evaluated using the gold standard of randomized controlled trials. More commonly used approaches are quasi-experimental natural experiments, with before-and-after data obtained from archival analysis of official statistics or surveys, and comparisons with populations who have not been exposed to the intervention, where possible. A narrative review approach was used given the need to cover a wide range of study designs and issues which do not lend themselves to a systematic review [7]. Available disorderspecific evidence on the most effective and cost-effective interventions provided by mental health volume of Disease Control Priorities (third edition) [5] was used; supplemented by a narrative review of the best evidence where necessary. The authors of this manuscript provided expert consensus on whether interventions were classified as "best practice" on the basis of whether evidence from quasi-experimental natural experiments was available in LMICs as well as evidence of cost-effectiveness in LMICs. "Good practice" interventions were identified on the basis of whether there was limited but promising local small scale studies in LMICs, and where further research was still needed.

\section{Community-level interventions}

Studies on interventions at the community level in LMICs were identified on the same basis as for the population-level. Many of these interventions have a prevention and promotion focus, and expert consensus by the authors of this manuscript was used to evaluate effectiveness using the ACE-Prevention framework [8]. The ACE (Assessing Cost-Effectiveness in Prevention Project) grading system provides a single framework for the evaluation of evidence on clinical, public health, and behavioral interventions. Using this system, sufficient evidence is when there is at least one systematic review of randomized control trials (RCTs), as well as several good quality RCTs or several high-quality pseudo-RCTs using alternate allocation or another method, or non-RCTs with comparative groups to exclude chance. Limited evidence is when the effect is probably not due to chance, but bias cannot be ruled out as a possible explanation for the effect. We have classified this evidence as promising. Inconclusive evidence is when there is no evidence of 
systematic reviews or RCTs, although there may be a few poor quality pseudo-randomized/non-RCTs with comparative groups or cohort studies.

"Best-practice" interventions were identified on the basis of whether there was sufficient evidence of their effectiveness in LMICs using the ACE grading system, evidence of their cost-effectiveness in HICs, and evidence of their feasibility in relation to cultural acceptability and capacity for scale-up in resource-constrained settings in LMICs. "Good practice" interventions were identified on the basis of sufficient evidence of their effectiveness in HICs and limited but promising evidence of their effectiveness in LMICs, using the ACE framework.

\section{Results}

Details of the specific studies reviewed can be found in Additional file 1: Table S1.

\section{Population level \\ Legislation and regulations for promotion and primary prevention}

a. Reducing demand for alcohol products

The prevention of harmful alcohol use in adults provides benefits across diseases. It can help prevent the development of alcohol use disorder and unipolar depression; other chronic non-communicable diseases, such as cardiovascular disease, diabetes, and cirrhosis of the liver; and help prevent accidental and intentional injuries or death [9].

Evidence from HICs and LMICs indicates that the most cost-effective strategy for reducing alcohol consumption is increased taxation and/or pricing of alcohol products, followed by bans on alcohol advertising, restrictions on access to alcohol, and enforcement of drinking and driving legislation $[9,10]$. Laws and regulations reducing demand for alcohol products are thus considered "best practice". Raising taxes is, however, less effective in countries with lower levels of alcohol consumption where other targeted interventions, such as enforcing drunk-driving legislation and brief screening and intervention (BSI), are more effective [9]. Regulations may also be less effective in countries where alcohol can be easily acquired through the unregulated/black market/home brews.

b. Restricting access to means of suicide

Three quarters of the 804,000 deaths by suicide that are estimated globally for 2012 were from LMICs [11]. Regulations restricting access to common, regional-specific, lethal means of suicide have been effective in reducing suicide rates in HICs and LMICs $[11,12]$ as well as being cost-effective [13], and is thus considered "best practice". The impact of the introduction of pesticide regulations on the reduction of suicides in Sri Lanka provides an example of how this strategy has been effectively applied in LMICs, where the suicide rate of 47 deaths per 100,000 in 1995 was halved from 1996 to 2005, with a reduction of 19769 suicides, as a result of the banning of all WHO toxicity Class pesticides in 1995 and the banning of endosulfan, a Class II toxicity pesticide in 1998 [14]

c. Other multi-sectoral public policies with promising evidence to promote mental health and prevent MNS disorders in children and adults

During childhood, child maltreatment is a risk factor for the development of MNS disorders [15]. Sufficient evidence from HICs [16] and some limited but promising evidence from LMICs indicates that the enactment of child protection laws for children living outside of the family have health and safety benefits for these children [17] [15], although further research to assess the benefits for children within their families of origin is indicated. Limited but promising evidence from Honduras also suggests that improved control of neurocysticercosis, (a common cause of epilepsy in LMIC) through deworming of humans, vaccination of pigs, improved sanitation, meat inspection, and improved pig farming, can lead to a reduction in symptomatic epilepsy in hyperendemic populations [18]. Given that the evidence for these interventions is still limited, they are recommended as "good practice" at the population level.

\section{Information and awareness campaigns for promotion and primary prevention}

Information and public awareness campaigns employ broad strategies and messages to promote mental health literacy, defined as knowledge and beliefs about mental disorders to aid their recognition, management, and prevention [19]; as well as reduce stigma and discrimination and hence help protect people with MNS disorders. They disseminate information about signs and symptoms of MNS disorders, locations where people may receive help, facts and figures about prevalence, risk factors, and evidence to combat stigmatizing beliefs.

Most information and awareness programs represent low-intensity interventions aimed at large numbers of people, often through print media, recordings, radio, television, cinema, mobile phones, and the Internet [20, 21]. There is a growing evidence base from HICs of the effectiveness of large-scale efforts for increasing knowledge and recognition of MNS disorders [22], improving attitudes [23, 24], and reducing discrimination in a costeffective manner [25-30]. Although information and awareness programs often cover a broad range of MNS disorders, most focus on mental rather than neurological disorders, with one randomized controlled trial from 
Hong Kong showing that exposing individuals to information about dementia through vignettes led to a statistically significant reduction in stigma [31].

With regard to anti-stigma interventions specifically, a systematic review of interventions in HICs by Clement and colleagues showed that mass media awareness programmes may reduce prejudice; although fewer studies have investigated their effects on actual discrimination [21]. A review by Corrigan and colleagues examined anti-stigma approaches that incorporated elements of education, protest, or contact [32]. In-person contact interventions yielded the greatest effect in adults; education was most effective among adolescents. One challenge is to deliver these types of interventions on a mass scale to the public, with some evidence of the effectiveness of virtual contact via film or video [33]; as well as the feasibility of achieving positive intergroup contact via large public events [34].

There is a paucity of evidence for the effectiveness of mass awareness programmes to improve mental health literacy and reduce stigma in LMICs. One study in the Russian Federation investigated the effectiveness of an anti-stigma computer program for improving knowledge and attitudes as well as reducing social distance among university students [35]. Students were randomized to one of three groups: a computer program group, a reading group, or a control group. At 6 months follow-up, while the reading group showed some improvement in attitudes; all stigma outcomes were significant in the computer program group.

Based on sufficient evidence from HICs and emerging evidence from LMICs, mass public awareness campaigns are recommended as "good practice"; with more research in LMICs being particularly needed.

\section{Legislation and regulations to improve identification, treatment and care of persons with mental disorders}

Evidence of the impact of legislation and regulations for improved identification, treatment and care is lacking from both HICs and LMICs. It would, however, be reasonable to assume that up-to-date mental health laws and regulations that are in line with the best practice and human rights standards such as those outlined by the WHO QualityRights [36] would promote protection of persons with mental disorders, but have not been identified as such here given the lack of evidence.

\section{Community level \\ Workplaces}

Promotion and primary prevention Workplace settings provide an ideal setting for the provision of promotion and prevention interventions for adults. Evidence from $\mathrm{HICs}$ indicates that individual and organizational level interventions improve and maintain mental health in the workplace, including screening and cognitive behavioral therapy (CBT) for preclinical symptoms of depression and anxiety to prevent the onset of these disorders [37, 38]. The evidence base from LMICs is, however, sparse. Limited but promising evidence of effectiveness of primary prevention and promotion is provided by the New SOLVE training package, developed by the International Labour Organization [39]. This package focuses on integrating mental health promotion strategies, such as stress reduction and awareness of alcohol and drug misuse, into occupational health and safety policies [39]. These integrated mental health strategies in the workplace are recommended as "good practice", given limited but promising evidence, with a recommendation that more robust evidence be generated from LMICs.

Identification and case detection Evidence is available from HICs on the identification and case detection of MNS disorders in the workplace. An evaluation of the APPRAND program in France found that individuals on sick leave who were screened and identified as having anxiety and depressive disorders by company health physicians, and who received an awareness-raising and referral intervention, displayed higher remission and recovery rates, compared to individuals in other centres who were not screened and who did not receive the intervention [40]. Positive effects have been reported for a mental health first aid course in Australia [41] that included training in screening for mental disorders. There have also been encouraging results in the US for migraine/headache management programs that have included screening questionnaires and educational initiatives, which resulted in an increase in the number of participants seeking help from a physician, an improvement in headache symptoms, and a reduction in absenteeism amongst those affected and the resulting employer cost burden [42, 43]. There is, however, insufficient evidence from LMICs for screening of MNS disorders in workplace settings to be recommended yet, with further research in LMICs required.

Treatment, care, and rehabilitation Interventions for the treatment, care, and rehabilitation of people with MNS disorders in the workplace have been shown to be effective in HICs. For people with common mental health problems, individual therapies rather than organizational interventions have been the most effective; in particular, CBT [4446] (either face-to-face or more questionably via computer software) $[47,48]$. To a lesser extent, exercise and relaxation interventions, such as aerobic or meditation sessions, have been beneficial [49]. Independent case management by third-party specialists, such as labour experts or employment advisors, has also shown a positive impact on people with common mental disorders when combined with psy- 
chological therapies, such as CBT [46]. Multimodal interventions may be more effective than single interventions [44]. With regard to severe mental disorders, there is also sufficient evidence from HICs of the benefits of supported employment, for example, individual placement and support (IPS), in helping people obtain competitive employment [50-52]. For neurological disorders, a few studies have shown positive effects (though with mixed results) of educational and physical programs that have been implemented in workplace settings in Italy and Finland to reduce headaches and neck/shoulder pain [53-55].

Overall, evidence for the treatment, care and rehabilitation of MNS disorders in the workplace from LMICs is insufficient for recommendations to be made yet, with one RCT in South Africa showing that a workplace intervention consisting of workability assessments and workplace visits was able to facilitate return to work for stroke patients [56]. Further research is recommended in LMICs on the effectiveness of training in first-level management of acute symptoms, particularly CBT, for anxiety or depression (possibly combined with independent case management), supported employment for severe mental disorder, and educational, physical and return-towork interventions for neurological disorders.

\section{Schools}

\section{Promotion and primary prevention}

a. Information and awareness

Examples of robust evaluations of broad information and awareness interventions addressing MNS literacy in schools are more generally available in HICs [57-59]. In LMICs, one study using a randomized control design was sourced. It was performed in rural secondary schools in Pakistan led by health care professionals, and involved a short training course for teachers, having a co-constructed educational program of lectures and several participatory activities. The study assessed changes in knowledge and attitudes 4 months after the start of the program. Improvements were noted among schoolchildren, their parents, friends, and neighbours. In the control group, there were improvements only among schoolchildren and their friends [60]. For neurological disorders, only studies in HICs could be sourced. Hip Hop Stroke, is an example of an information and awareness programme for children (8-12 years) from schools in a high risk stroke neighbourhood in the United States that showed improved knowledge of stroke symptoms and behavioral intent to call 911 [61]. Given promising emerging evidence from LMICs of the positive impact of information and awareness interventions in schools, these pro- grammes are recommended as "good practice"; with further research recommended.

b. Social and emotional learning (SEL) interventions Studies from HICs and LMICs indicate that universal SEL programs that promote social and emotional competencies can improve social and emotional functioning and academic performance in exposed children, as well as reduce risk behaviour. Systematic reviews from HICs show that universal SEL interventions in primary and post-primary schools promote children's social and emotional functioning and academic performance, including evidence of long-term benefits [62-67]. Interventions that employ a whole-school approach where SEL is supported by a school ethos and a physical and social environment that is health enabling involving staff, students, parents, school environment and local community are most effective, and have additionally been shown to reduce bullying [68], with bullying in childhood and adolescence a risk factor for the development of mental disorders [69].

A systematic review [70], as well as other studies [7174] also provide sufficient evidence of the beneficial effects of universal SEL programs in LMICs. Delivery of these interventions by teachers and school counsellors through integrating social and emotional learning, including life skills development into the school curriculum, is feasible as demonstrated by the Healthwise program in South Africa [73]. However, fidelity can affect the impact of SEL interventions; teacher training, support, and supervision are needed, as is attention to the school environment [75]; suggesting that integration into a whole school approach that pays attention to contextual issues would be optimal. Targeted/indicated interventions for high-risk children (children having had experiences that elevate their vulnerability of developing a MNS disorder/ show pre-clinical symptoms of a disorder) that promote coping and resilience, including cognitive skills training have been found to help prevent the onset of anxiety, depression, and suicide in HICs [76-78]. Several RCTs of targeted interventions for vulnerable children have also been conducted in LMICs [79]. Classroom-based interventions for vulnerable children, especially those orphaned by HIV or living in areas of conflict, have shown in some studies to improve general psychological health and coping [80-83]; however, these effects are contingent on individual variables, such as age and gender, as well as contextual variables, such as conflict, displacement, and family functioning [84], and may be better suited for children with less severe risks and difficulties [79]. Economic analyses from HICs indicate that SEL interventions in schools are cost-effective, result- 
ing in savings from better health outcomes, as well as reduced expenditures in the criminal justice system $[85,86]$. Based on sufficient evidence as well as feasibility, universal school-based SEL interventions are recommended as "best practice" interventions in LMICs, and targeted school-based interventions as "good practice", with more research on the role of individual and contextual variables on mental health outcomes required.

Identification and case detection Many people with MNS disorders have their onset during childhood and adolescence, and these early difficulties are likely to be present in the school context. Teachers have a critical role in identifying emerging problems and taking appropriate action, with RCTs from HICs providing evidence for training in indicated screening of developmental and behavioral disorders in schools. Mental health first aid for high school teachers has been tested using a cluster RCT [87]. While data from LMICs are more limited, evidence supports the feasibility and reliability of identifying and assessing MNS disorders in primary and secondary school students [8891]. In Haiti, a 2.5 day training program for secondary school teachers focused on recognizing, responding, and referring students at risk for MNS disorders following the earthquake in 2010. The intervention was associated with improvements in knowledge, attitudes, and recognition of MNS problems [92]. In terms of neurological disorders, in Chandigarh city, India, a one-off educational intervention package improved teachers' knowledge, attitudes and skills regarding epilepsy immediately after the intervention, and at 3-month follow-up. However, it was noted that further workshops would be required for long-term benefit [93].

Given sufficient evidence from HICs as well as emerging promising evidence from LMICs, identification and case detection in schools of children with MNS disorders are recommended as "good practice"; with further research in LMICs required.

Treatment, care, and rehabilitation There is sufficient research evidence of the effective treatment and management of people with some types of MNS disorders in schools in HICs. A meta-analysis that examined the effectiveness of various types of school-based CBT for young people with anxiety and depression showed significant reductions in symptoms overall [94]. School-based interventions for attention-deficit/hyperactivity disorder (ADHD) have been found to be promising in younger children but less so for adolescents; these interventions lack robust long-term program effectiveness data, as well as cost effectiveness data [95]. Effective ADHD inter- ventions for academic and behavioral outcomes involve contingency management, academic intervention, and cognitive-behavioral interventions [96]. For neurological disorders, a classroom-based headache prevention program in Germany found a small but significant reduction in reported tension-type headaches 7 months following the intervention [97].

Evidence from HICs indicates that children with emotional and behavioural disorders benefit from classroom environments that are predictable and consistent, with clear structures and rules; such settings are associated with improved classroom, peer behavior, and enhanced learning [98]. Interventions that use direct instruction, peer tutoring, and behaviorally based procedures, such as time delay prompting, trial and error, and differential reinforcement, hold promise [99].

Evidence from LMICs for treatment, care and rehabilitation for children with MNS disorders is equivocal. An $\mathrm{RCT}$ of a universal school-based intervention in reducing depressive symptoms was conducted in Chile. Using CBT techniques delivered by non-specialists, this intervention comprised 11 1-h weekly and two booster classroom sessions. Although it was a universal intervention, the study analysed subgroups of young people with high depression scores. It showed no clinically significant difference between the intervention and control groups, and no evidence of effect modification by severity of symptoms [100]. There have also been a few trials of the classroombased intervention (CBI) incorporating cognitive behavioral techniques and creative expressive elements to help children with depressive, anxiety, and posttraumatic stress disorder (PTSD) symptoms in complex emergencies in LMICs $[81,84,101,102]$. The emerging evidence on the effectiveness of treatment of PTSD and depressive symptoms is inconsistent; with CBI having more consistent preventive benefits, particularly when risks are less severe. CBI can thus not be recommended for treatment of these conditions in conflict-affected children [79]. Given the equivocal evidence from LMICs, further research generating positive outcomes for the treatment care and rehabilitation for children with MNS disorders in schools is required before recommendations for LMICs can be made.

\section{Neighbourhood/community groups}

Primary prevention and promotion There is an array of primary prevention and promotion interventions delivered in neighbourhood settings or through community groups. These include programs on early child enrichment/preschool educational programmes, communitybased parenting, and gender and/or economic empowerment interventions. 
a. Child enrichment and preschool educational programs

Robust evidence from HICs demonstrates the effectiveness and cost-effectiveness of early child enrichment and preschool educational programs (which promote cognitive stimulation and social interaction) on children's social and emotional wellbeing, cognitive skills, problem behaviors, and school readiness $[65,103,104]$; as well as evidence of the long-term effects on school attainment, social gains, and occupational status in HICs [105]. The evidence from LMICs is promising $[15,106-109]$ and these interventions are thus recommended as "good practice".

b. Parenting interventions

The effectiveness of parenting interventions for promoting child emotional and behavioral adjustment in HICs, particularly in infants and younger children, has been demonstrated [110], as well as the cost-effectiveness of programs for the prevention of conduct disorders [85]. There is also sufficient evidence from LMICs of the effectiveness and feasibility of parenting programs to enhance mother-child interaction during infancy for these interventions to be considered "best practice" [15, 111-116]. Many of these interventions are delivered at health centres or utilize a home visitation program and therefore overlap with the primary health care facility platform. The effectiveness of community parenting programs in HICs for preventing internalizing and externalizing disorders in older children (pre-school and schoolgoing), has also been demonstrated in HICs [117] with promising evidence in LMICs [113, 118-120]; and these interventions are thus recommended as "good practice".

c. Gender equity and/or economic empowerment interventions

A growing body of research indicates the feasibility and benefits for vulnerable adolescents and adults of gender equity and/or economic empowerment programs in LMICs [121-127]. Microfinance (microcredit and micro-savings) schemes for poor people in sub-Saharan Africa that incorporate gender empowerment, health and education training components are seemingly more effective in terms of mental health benefits over stand-alone programmes [128, 129]. Given promising evidence, these programs are recommended as "good practice".

Identification and case detection Mental health first aid training at the community level involves training members to identify when a person is developing a mental dis- order, is suicidal, or is in crisis; to know how to manage the situation; and to know appropriate facilities for referral [19]. Evidence for feasible and effective identification training programs of non-mental health workers is particularly robust for police officers and community health workers in HICs and LMICs. Given that community health workers may operate out of health centres or utilize a home visitation program, these interventions may overlap with services provided by the health system. With regard to neurological disorders, research from HICs suggests that trained community health workers can facilitate early detection of dementia in resource poor communities [130]. Moreover, if screening leads to early intervention within a year of detection, it could be associated with cost savings through reduced healthcare costs in the long run [131]. Mental health first aid (MHFA) training of community members generally has also been found to increase knowledge, reduce stigma, and increase helping behaviors in HICs. While MHFA is being rolled out in a number of LMICs, evidence of effectiveness is still required [132]. With sufficient evidence from HICs, as well as emerging promising evidence from LMICs of the effectiveness of training of non-mental health workers and community members in the identification and case detection, it is recommended as "good practice"; with further research in LMICs recommended.

Treatment, care, and rehabilitation Policy shifts to deinstitutionalization and decentralized care in many LMICs are heightening the need for community-based treatment and rehabilitation for mental disorders. There is emerging evidence of the effectiveness of collaborative community-based care interventions using a tasksharing approach in LMICs. The Community Care for People with Schizophrenia in India (COPSI) intervention compared the effectiveness of facility-based care with a collaborative community-based approach using a multicentre RCT. Findings demonstrated that the collaborative community-based approach in combination with facility-based care was most effective and was associated with improvements in disability and symptoms [133]. Observational studies in India also suggest that community-based rehabilitation and microfinance initiatives can improve symptoms and reduce disability [134-136]. More targeted interventions, such as psycho-education [137-143]; adherence support [144, 145], and self-help groups also show promise in LMICs. Most studies focus on psychosis; however, community-based interventions can be beneficial for other MNS disorders as well. In this respect, a cluster RCT demonstrated that using community counselors for the treatment of maternal depression through a home visitation programme was associ- 


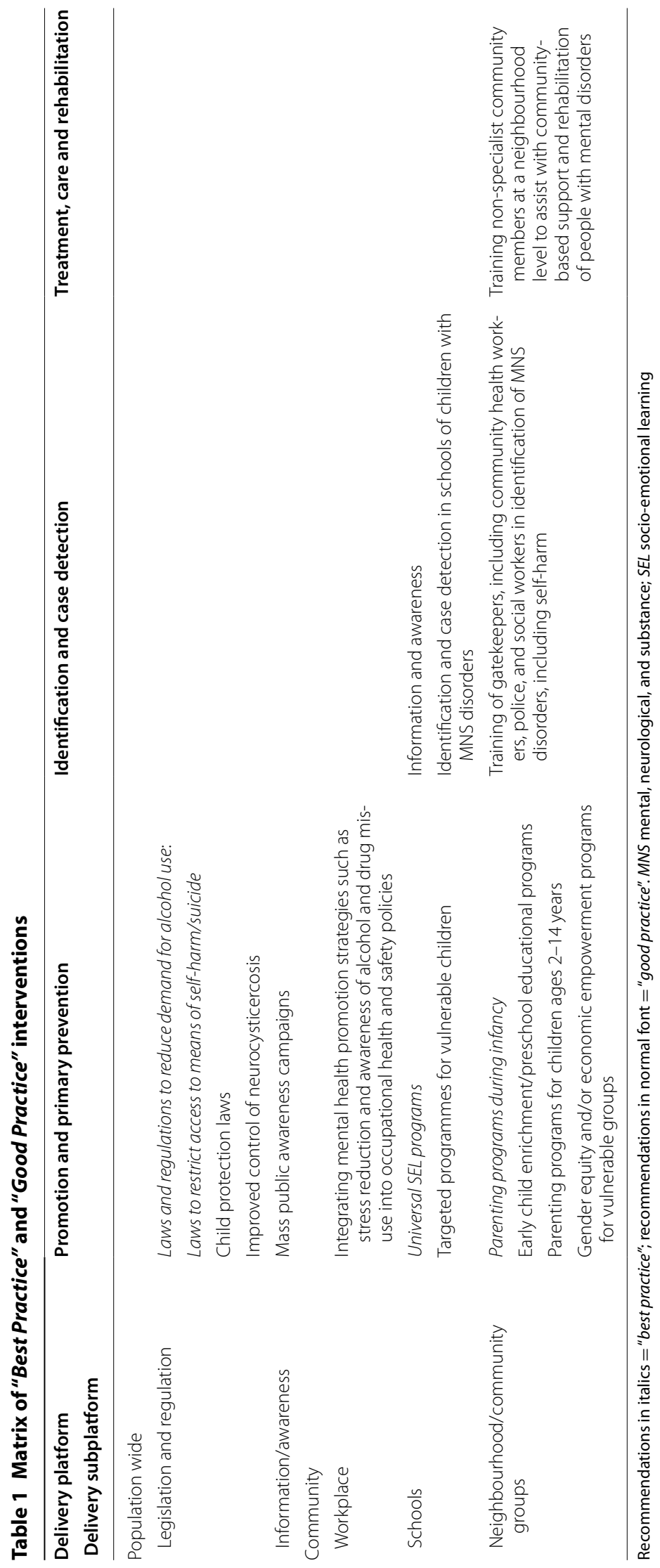


ated with greater recovery [146] and a home-based care support programme for carers of people with dementia showed improved mental health outcomes for the carers [147]. These interventions are recommended as good practice in LMICs, and further research on the effectiveness of interventions using non-specialists, including traditional healers, at a neighbourhood level or through community groups are recommended.

\section{Discussion}

Interventions identified as being "best practice" and "good practice" are summarized in Table 1.

Interventions at the population level have a broad reach, promoting and protecting the mental health of the entire population through legislation, regulations, and public campaigns. There is good evidence that legislation and regulations to control alcohol demand can reduce alcohol consumption in LMICs at minimal cost, and laws and regulations restricting access to lethal means of suicide that are region-specific can reduce suicide rates in LMICs. There is also promising evidence of the benefits of mass public awareness campaigns on reducing stigma and discrimination; as well as the mental health benefits of child protection laws, and laws and regulations for improved control of neurocysticercosis in reducing epilepsy specifically.

At the community level, there is evidence from LMICs that neighbourhoods are an important setting for the delivery of primary prevention and promotion interventions. In particular, there is strong evidence that parenting programs during infancy, that promote mother-child interaction, are beneficial for long term mental health. There is also promising evidence of the mental health benefits of early child enrichment/preschool educational programs, parenting programs for older children, and gender equity and/or economic empowerment programs for vulnerable groups. Neighbourhoods are also important settings for the identification of people with MNS disorders, using trained community gatekeepers.

Schools are a particularly important setting for mental health promotion and prevention interventions in children; as well as identification. In particular, there is sufficient evidence of universal SEL programs for improving mental health outcomes in children and to a lesser degree targeted programmes in LMICs. Schools can also be used for the delivery of information and awareness programmes.

Finally, the workplace presents an opportune setting for mental health promotion and prevention activities for adults, with emerging evidence in LMICs of the benefits of integrating stress reduction programmes and awareness-raising, particularly of alcohol and drug misuse.

\section{Conclusion}

Although much attention has historically been paid to the health sector for the delivery of mental health services, greater consideration of interventions at the population- and community-levels are necessary, particularly for the delivery of mental health promotion and prevention interventions, as well as for the early identification of mental disorders, especially in children and adolescents, and to a lesser degree, care and rehabilitation. This review has identified "best practice" and "good practice" interventions at the population and community levels; providing evidence of potential opportunities and synergies for the strengthening of mental health and human capital development across multiple sectors in LMICs. Harnessing these opportunities, however, requires awareness of mental health as a public health and social development priority and political will to engage in collaborative arrangements across different sectors.

\section{Additional file}

Additional file 1: Table S1. Evidence of primary prevention and promotion interventions at the population and community level platform.

\section{Authors' contributions}

IP and GT led the review and contributed to the review material and drafting of manuscript. SE, MS, MMB, DC, PG and C.O.E all contributed to the review and drafting of the manuscript. All authors read and approved the final manuscript.

\section{Author details}

${ }^{1}$ Centre for Rural Health, School of Nursing and Public Health and School of Applied Human Sciences, University of KwaZulu Natal, Durban, South Africa. ${ }^{2}$ Centre for Global Mental Health, Institute of Psychiatry, Psychology and Neuroscience, King's College London, London, UK. ${ }^{3}$ World Health Organization Collaborating Centre for Health Promotion Research, National University of Ireland Galway, Galway, Ireland. ${ }^{4}$ Department of Mental Health and Substance Abuse, World Health Organization, Geneva, Switzerland. ${ }^{5}$ School of Applied Human Sciences, University of KwaZulu Natal, Durban, South Africa. ${ }^{6}$ Center for Tobacco Control Research and Education, University of California, San Francisco, USA.

\section{Acknowledgements}

The review was informed by the published chapter on population- and community- interventions for the mental health volume of Disease Control Priorities (third edition) [5].

\section{Competing interests}

The authors declare that they have no competing interests.

\section{Disclaimers}

GT is supported by the National Institute for Health Research (NIHR) Collaboration for Leadership in Applied Health Research and Care South London at King's College London Foundation Trust. GT acknowledges financial support from the Department of Health via the National Institute for Health Research (NIHR) Biomedical Research Centre and Dementia Unit awarded to South London and Maudsley NHS Foundation Trust in partnership with King's College London and King's College Hospital NHS Foundation Trust. GT is also supported by the European Union Seventh Framework Programme (FP7/20072013) Emerald project. The views expressed are those of the author(s) and not necessarily those of the NHS, the NIHR, the Department of Health or the 
European Union. DC is a staff member of the World Health Organization. The authors alone are responsible for the views expressed in this publication and they do not necessarily represent the decisions, policy or views of the World Health Organization.

Received: 3 July 2015 Accepted: 23 March 2016

Published online: 11 April 2016

\section{References}

1. Ngui EM, Khasakhala L, Ndetei D, Roberts LW. Mental disorders, health inequalities and ethics: a global perspective. Int Rev Psychiatr. 2010;22(3):235-44.

2. Murray CJ, Vos T, Lozano R, Naghavi M, Flaxman AD, Michaud C, et al. Disability-adjusted life years (DALYs) for 291 diseases and injuries in 21 regions, 1990-2010: a systematic analysis for the Global Burden of Disease Study 2010. Lancet. 2013;380(9859):2197-223.

3. World Health Organization. mhGAP intervention guide for mental, neurological and substance use disorders in non-specialized health settings: Mental Health Gap Action Programme (mhGAP). 2010.

4. Dua T, Barbui C, Clark N, Fleischmann A, Poznyak V, van Ommeren M et al. Evidence-based guidelines for mental, neurological, and substance use disorders in low-and middle-income countries: summary of WHO recommendations. PLoS Med. 2011;8(11):e1001122.

5. Petersen I, Evans-Lacko S, Semrau M, Barry MM, Chisholm D, Gronholm $P$, et al. Population and community level interventions. In: Patel $\mathrm{V}$, Chisholm D, Dua T, Laxminarayan R, Medina-Mora ME, editors. Disease control priorities, vol. 4. 3rd ed. Mental, neurological and substance use disorders. Washington, DC: World Bank; 2015. p. 183-200.

6. Barry MM, Clarke AM, Petersen I. Promotion of mental health and prevention of mental disorders: priorities for implementation. East Mediterr Health J. 2015:21(7):503-11.

7. Educational Research Review. An authors' guide to writing articles and reviews for Educational Research Review (2009). http://www.elsevier com/framework_products/promis_misc/edurevguidetowriting.pdf. Accessed 21 Jan 2014

8. Carter R, Stone C, Vos T, Hocking J, Mihalopoulos C, Peacock S, et al. Trial of program budgeting and marginal analysis (PBMA) to assist cancer control planning in Australia. Canberra: Commonwealth Department of Health and Aged Care; 2000

9. Rehm J, Chisholm D, Room R, Lopez A. Alcohol. In: Jamison D, Breman J, Measham A, Alleyne G, Evans D, Jha P, et al., editors. Disease control priorities in developing countries. 2nd ed. New York: Oxford University Press; 2006. p. 887-906.

10. Medina-Mora ME, Monteiro M, Room R, Rehm J, Jernigan D, SánchezMoreno D, et al. Alcohol Use and Alcohol Use Disorders. In: Patel V, Chisholm D, Dua T, Laxminarayan R, Medina-Mora ME, editors. Disease Control Priorities, vol. 4. 3rd ed. Mental, neurological and substance use disorders. Washington, DC: World Bank; 2015. p. 127-43.

11. Vijayakumar L, Phillips M, Silverman M, Gunnell D, Carli V. Suicide in low and middle income countries. In: Patel V, Chisholm D, Dua T, Laxminarayan R, Medina-Mora ME, editors. Disease Control Priorities, vol. 4 3rd ed. Mental, neurological and substance use disorders. Washington, DC: World Bank; 2015. p. 163-81.

12. van der Feltz-Cornelis CM, Sarchiapone M, Postuvan V, Volker D, Roskar S, Grum AT, et al. Best practice elements of multilevel suicide prevention strategies: a review of systematic reviews. Crisis. 2011;32(6):319-33.

13. Levin C, Chisholm D. Cost and cost-effectiveness of interventions, policies, and platforms for the prevention and treatment of mental, neurological, and substance use disorders. In: Patel V, Chisholm D, Dua T, Laxminarayan R, Medina-Mora ME, editors. Disease control priorities, vol. 4. 3rd ed. Mental, neurological, and substance use disorders. Washington, DC: World Bank; 2015. p. 219-36.

14. Gunnell D, Fernando R, Hewagama M, Priyangika WD, Konradsen F, Eddleston M. The impact of pesticide regulations on suicide in Sri Lanka. Int J Epidemiol. 2007;36(6):1235-42.

15. Scott J, Mihalopoulos C, Erskine H, Roberts J, Rahman A. Childhood mental and developmental disorders: interventions for low and middle income countries. In: Patel V, Chisholm D, Dua T, Laxminarayan
R, Medina-Mora ME, editors. Disease control priorities, vol. 4. 3rd ed. Mental, neurological and substance use disorders. Washington, DC: World Bank; 2015. p. 145-61.

16. Save the Children UK. A rough guide to child protection systems. United Kingdom: 2009.

17. Fluke JD, Goldman PS, Shriberg J, Hillis SD, Yun K, Allison S, et al. Systems, strategies, and interventions for sustainable long-term care and protection of children with a history of living outside of family care. Child Abuse Negl. 2012;36(10):722-31.

18. Medina MT, Aguilar-Estrada RL, Alvarez A, Durón RM, Martínez L, Dubón $\mathrm{S}$, et al. Reduction in rate of epilepsy from neurocysticercosis by community interventions: the Salama, Honduras Study. Epilepsia. 2011;52(6):1177-85.

19. Jorm AF. Mental health literacy: empowering the community to take action for better mental health. Am Psychol. 2012;67(3):231-43.

20. Andreasen A. Social marketing in the 21st century. Thousand Oaks: Sage Publications; 2006.

21. Clement S, Lassman F, Barley E, Evans-Lacko S, Williams P, Yamaguchi $S$, et al. Mass media interventions for reducing mental health-related stigma. Cochrane Database Syst Rev. 2013;7:CD009453.

22. Jorm AF, Christensen H, Griffiths KM. The impact of beyondblue: the national depression initiative on the Australian public's recognition of depression and beliefs about treatments. Aust N Z J Psychiatr. 2005;39(4):248-54.

23. Dunion L, Gordon L. Tackling the attitude problem. The achievements to date of Scotland's' see me'anti-stigma campaign. Mental Health Today (Brighton, England). 2005;22

24. Evans-Lacko S, Malcolm E, West K, Rose D, London J, Rusch N, et al Influence of time to change's social marketing interventions on stigma in England 2009-2011. Br J Psychiatr Suppl. 2013;55:s77-88.

25. Corker E, Hamilton S, Henderson C, Weeks C, Pinfold V, Rose D, et al. Experiences of discrimination among people using mental health services in England 2008-2011. Br J Psychiatr Suppl. 2013;55:558-63.

26. Henderson C, Corker E, Lewis-Holmes E, Hamilton S, Flach C, Rose $D$, et al. England's time to change antistigma campaign: one-year outcomes of service user-rated experiences of discrimination. Psychiatr Serv. 2012;63(5):451-7.

27. Thornicroft C, Wyllie A, Thornicroft G, Mehta N. Impact of the "Like minds, like mine" anti-stigma and discrimination campaign in New Zealand on anticipated and experienced discrimination. Aust N Z J Psychiatr. 2014;48(4):360-70

28. Evans-Lacko S, Henderson C, Thornicroft G, McCrone P. Economic evaluation of the anti-stigma social marketing campaign in England 2009-2011. Br J Psychiatr Suppl. 2013;55:s95-101.

29. McCrone P, Knapp M, Henri M, McDaid D. The economic impact of initiatives to reduce stigma: demonstration of a modelling approach. Epidemiologia e psichiatria sociale. 2010;19(2):131-9.

30. Thornicroft G, Alem A, Santos RA, Barley E, Drake RE, Gregorio G, et al. WPA guidance on steps, obstacles and mistakes to avoid in the implementation of community mental health care. World Psychiatr Off J World Psychiatr Assoc. 2010;9(2):67-77.

31. Cheng S-T, Lam LC, Chan LC, Law AC, Fung AW, W-c Chan, et al. The effects of exposure to scenarios about dementia on stigma and attitudes toward dementia care in a Chinese community. Int Psychogeriatr. 2011;23(09):1433-41.

32. Corrigan PW, Morris SB, Michaels PJ, Rafacz JD, Rusch N. Challenging the public stigma of mental illness: a meta-analysis of outcome studies. Psychiatr Serv. 2012;63(10):963-73.

33. Clement S, van Nieuwenhuizen A, Kassam A, Flach C, Lazarus A, de Castro $\mathrm{M}$, et al. Filmed v. live social contact interventions to reduce stigma: randomised controlled trial. Br J Psychiatr. 2012;201(1):57-64.

34. Evans-Lacko S, London J, Japhet S, Rusch N, Flach C, Corker E, et al. Mass social contact interventions and their effect on mental health related stigma and intended discrimination. BMC Public Health. 2012:12:489.

35. Finkelstein J, Lapshin O, Wasserman E. Randomized study of different anti-stigma media. Patient Educ Couns. 2008;71(2):204-14.

36. World Health Organization. WHO QualityRights tool kit to assess and improve quality and human rights in mental health and social care facilities. Geneva: World Health Organization; 2012. 
37. Nytro K, Saksvik PO, Mikkelsen A, Bohle P, Quinlan M. An appraisal of key factors in the implemention for occupational stress interventions. Work Stress. 2000;14(3):213-25.

38. World Health Organization. Mental health and work: impact, issues and good practices. Geneva: World Health Organization; 2000

39. Probst TM, Gold D, Caborn J. A preliminary evaluation of SOLVE: addressing psychosocial problems at work. J Occup Health Psychol. 2008;13(1):32-42.

40. Godard C, Chevalier A, Lecrubier Y, Lahon G. APPRAND programme: an intervention to prevent relapses of anxiety and depressive disordersfirst results of a medical health promotion intervention in a population of employees. Eur Psychiatr. 2006;21(7):451-9.

41. Kitchener B, Jorm A. Mental health first aid training in a workplace setting: a randomized controlled trial. BMC Psychiatr. 2004;4:23.

42. Page MJ, Paramore LC, Doshi D, Rupnow MF. Evaluation of resource utilization and cost burden before and after an employer-based migraine education program. J Occup Environ Med. 2009;51(2):213-20.

43. Schneider WJ, Furth PA, Blalock TH, Sherrill TA. A pilot study of a headache program in the workplace: the effect of education. J Occup Environ Med. 1999;41(3):202-9.

44. British Occupational Health Research Foundation (BOHRF). Workplace interventions for people with common mental health problems: evidence review and recommendations. London: BOHRF; 2005.

45. Hill D, Lucy D, Tyers C, James L. What works at work? Review of evidence assessing the effectiveness or workplace interventions to prevent and manage common health problems. Leeds: Health Work and Wellbeing Delivery Unit; 2007.

46. Seymour L. Common mental health problems at work: What we now know about successful interventions. A progress review. London: Sainsburys Centre for Mental Health; 2010.

47. Grime P. Computerized cognitive behavioural therapy at work: a randomized controlled trial in employees with recent stress-related absenteeism. Occup Med. 2004;54(5):353-9.

48. van der Klink J, Blonk R, Schene A, van Dijk F. The benefits of interventions for work-related stress. Am J Public Health. 2001;91(2):270-6.

49. Graveling R, Crawford J, Cowie H, Amati C, Vohra S. A review of workplace interventions that promote mental wellbeing in the workplace. Edinburgh: Institute of Occupational Medicine; 2008.

50. Crowther R, Marshall M, Bond G, Huxley P. Helping people with severe mental illness to obtain work: systematic review. Br Med J. 2001;322:204-8

51. Dickson K, Gough D. Supporting people in accessing meaningful work: Recovery approaches in community-based adult mental health services. London: Social Care Institute for Evidence; 2008.

52. McDaid D. Mental health in workplace settings. Consensus paper. Luxembourg: European Communities; 2008.

53. Mongini F, Evangelista A, Milani C, Ferrero L, Ciccone G, Ugolini A, et al. An educational and physical program to reduce headache, neck/shoulder pain in a working community: a cluster-randomized controlled trial. PLoS One. 2012;7(1):e29637.

54. Rota E, Evangelista A, Ciccone G, Ferrero L, Ugolini A, Milani C, et al. Effectiveness of an educational and physical program in reducing accompanying symptoms in subjects with head and neck pain: a workplace controlled trial. J Headache Pain. 2011;12(3):339-45.

55. Sjögren T, Nissinen KJ, Järvenpää SK, Ojanen MT, Vanharanta H, Mälkiä EA. Effects of a workplace physical exercise intervention on the intensity of headache and neck and shoulder symptoms and upper extremity muscular strength of office workers: a cluster randomized controlled cross-over trial. Pain. 2005;116(1):119-28.

56. Ntsiea MV. The effect of a workplace intervention programme on return to work after stroke. Johannesburg: Faculty of Health Sciences, University of the Witwatersrand; 2013.

57. Pinfold V, Toulmin H, Thornicroft G, Huxley P, Farmer P, Graham T. Reducing psychiatric stigma and discrimination: evaluation of educational interventions in UK secondary schools. Br J Psychiatr. 2003;182(4):342-6.

58. Swartz KL, Kastelic EA, Hess SG, Cox TS, Gonzales LC, Mink SP, et al. The effectiveness of a school-based adolescent depression education program. Health Educ Behav. 2010;37(1):11-22.

59. Watson AC, Otey E, Westbrook AL, Gardner AL, Lamb TA, Corrigan PW, et al. Changing middle schoolers'attitudes about mental illness through education. Schizophr Bull. 2004;30(3):563-72.
60. Rahman A, Mubbashar MH, Gater R, Goldberg D. Randomised trial of impact of school mental-health programme in rural Rawalpindi, Pakistan. Lancet. 1998;352(9133):1022-5.

61. Williams O, DeSorbo A, Noble J, Shaffer M, Gerin W. Long-term learning of stroke knowledge among children in a high-risk community. Neurology. 2012;79(8):802-6

62. Durlak JA, Weissberg RP, Dymnicki AB, Taylor RD, Schellinger KB. The impact of enhancing students' social and emotional learning: a meta-analysis of school-based universal interventions. Child Dev. 2011;82(1):405-32.

63. Lister-Sharp D, Chapman S, Stewart-Brown S, Sowden A. Health promoting schools and health promotion in schools: two systematic reviews. Health Technol Assess. 1999;3(22):1-207.

64. NICE. Social and emotional wellbeing in secondary education. NICE public health guidance 20. United Kingdom: National Institute of Health and Clinical Excellence; 2009.

65. Tennant R, Goens C, Barlow J, Day C, Stewart-Brown S. A systematic review of reviews of interventions to promote mental health and prevent mental health problems in children and young people. J Publ Mental Health. 2007;6(1):25-32.

66. Weare K, Nind M. Mental health promotion and problem prevention in schools: what does the evidence say? Health Promot Int. 2011;26(Suppl 1):i29-69.

67. Wells J, Barlow J, Stewart-Brown S. A systematic review of universal approaches to mental health promotion in schools. Health Educ. 2003;103(4):197-220.

68. Smith JD, Schneider BH, Smith PK, Ananiadou K. The effectiveness of whole-school antibullying programs: a synthesis of evaluation research. Sch Psychol Rev. 2004;33(4):547-60.

69. Scott JG, Moore SE, Sly PD, Norman RE. Bullying in children and adolescents: a modifiable risk factor for mental illness. Aust N Z J Psychiatr. 2014;48(3):209-12.

70. Barry MM, Clarke AM, Jenkins R, Patel V. A systematic review of the effectiveness of mental health promotion interventions for young people in low and middle income countries. BMC Publ Health. 2013;13(1):835.

71. De Villiers M, Van den Berg H. The implementation and evaluation of a resiliency programme for children. South Afr J Psychol. 2012;42(1):93-102.

72. Mueller J, Alie C, Jonas B, Brown E, Sherr L. A quasi-experimental evaluation of a community-based art therapy intervention exploring the psychosocial health of children affected by HIV in South Africa. Trop Med Int Health. 2011;16(1):57-66.

73. Smith EA, Palen L-A, Caldwell LL, Flisher AJ, Graham JW, Mathews C, et al. Substance use and sexual risk prevention in Cape Town, South Africa: an evaluation of the HealthWise program. Prev Sci. 2008;9(4):311-21.

74. Srikala B, Kishore KK. Empowering adolescents with life skills education in schools-school mental health program: does it work? Indian J Psychiatr. 2010;52(4):344.

75. Caldwell LL, Smith EA, Collins LM, Graham JW, Lai M, Wegner L, et al. Translational research in South Africa: evaluating implementation quality using a factorial design. Child Youth Care Forum. 2012;41(2):119-36.

76. Clarke GN, Hawkins W, Murphy M, Sheeber LB, Lewinsohn PM, Seeley $J R$. Targeted prevention of unipolar depressive disorder in an at-risk sample of high school adolescents: a randomized trial of a group cognitive intervention. J Am Acad Child Adolesc Psychiatr. 1995;34(3):312-21.

77. Jaycox LH, Reivich KJ, Gillham J, Seligman ME. Prevention of depressive symptoms in school children. Behav Res Ther. 1994;32(8):801-16.

78. Shucksmith J, Summerbell C, Jones S, Whittaker V. Mental well being of children in primary education (targeted/indicated activities). Teeside: University of Teeside; 2007

79. Fazel M, Patel V, Thomas S, Tol W. Mental health interventions in schools in low-income and middle-income countries. Lancet Psychiatr. 2014;1(5):388-98.

80. Ager A, Akesson B, Stark L, Flouri E, Okot B, McCollister F, et al. The impact of the school-based Psychosocial Structured Activities (PSSA) program on conflict-affected children in northern Uganda. J Child Psychol Psychiatr. 2011;52(11):1124-33.

81. Jordans MJ, Komproe IH, Tol WA, Kohrt BA, Luitel NP, Macy RD, et al. Evaluation of a classroom-based psychosocial intervention in 
conflict-affected Nepal: a cluster randomized controlled trial. J Child Psychol Psychiatr. 2010;51(7):818-26.

82. Khamis V, Macy R, Coignez V. The impact of the classroom/community/ camp-based intervention (CBI) program on Palestinian children. USA: Save the Children; 2004.

83. Qouta SR, Palosaari E, Diab M, Punamäki RL. Intervention effectiveness among war-affected children: a cluster randomized controlled trial on improving mental health. J Trauma Stress. 2012;25(3):288-98.

84. Tol WA, Komproe IH, Jordans MJ, Ndayisaba A, Ntamutumba P, Sipsma $H$, et al. School-based mental health intervention for children in waraffected Burundi: a cluster randomized trial. BMC Med. 2014;12(1):56.

85. Knapp M, McDaid D, Parsonage M. Mental Health Promotion and Prevention: the economic case. London: Personal Social Services Research Unit, London School of Economics and Political Science; 2011.

86. McCabe C. A systematic review of cost-effectiveness analyses of whole school interventions to promote children's mental health. Leeds: Leeds Institute of Health Sciences; 2007.

87. Jorm AF, Kitchener BA, Sawyer MG, Scales H, Cvetkovski S. Mental health first aid training for high school teachers: a cluster randomized trial. BMC Psychiatr. 2010;10:51.

88. Becker AE, Thomas JJ, Bainivualiku A, Richards L, Navara K, Roberts $\mathrm{AL}$, et al. Validity and reliability of a Fijian translation and adaptation of the eating disorder examination questionnaire. Int J Eat Disord. 2010;43(2):171-8.

89. Becker AE, Thomas JJ, Bainivualiku A, Richards L, Navara K, Roberts AL, et al. Adaptation and evaluation of the Clinical Impairment Assessment to assess disordered eating related distress in an adolescent female ethnic Fijian population. Int J Eat Disord. 2010;43(2):179-86.

90. Opoliner A, Blacker D, Fitzmaurice G, Becker A. Challenges in assessing depressive symptoms in Fiji: a psychometric evaluation of the CES-D. Int J Soc Psychiatr. 2013;60(4):367-76.

91. Vieira MA, Gadelha AA, Moriyama TS, Bressan RA, Bordin IA. Evaluating the effectiveness of a training program that builds teachers' capability to identify and appropriately refer middle and high school students with mental health problems in Brazil: an exploratory study. BMC Public Health. 2014;14(1):210

92. Eustache E BA, for Ekip Wozo. Developing research capacity for mental health interventions for youth in Haiti. In: Health Nlo, editor. Frontiers in neuroscience for global health/tenth anniversary of brain disorders in the developing world: research across the lifespan; Bethesda; 2014.

93. Goel S, Singh N, Lal V, Singh A. Evaluating the impact of comprehensive epilepsy education programme for school teachers in Chandigarh city, India. Seizure J Br Epilepsy Assoc. 2014;23(1):41-6.

94. Mychailyszyn MPBD, Read KL, Kendall PC. Cognitive-behavioral schoolbased interventions for anxious and depressed youth: a meta-analysis of outcomes. Clin Psychol Sci Pract. 2012;52(11):1124-33.

95. Kutcher S, Wei YF. Mental health and the school environment: secondary schools, promotion and pathways to care. Curr Opin Psychiatr. 2012;25(4):311-6.

96. DuPaul GE, Eckert TL, Vilardo B. The effects of school-based interventions for attention deficit hyperactivity disorder: a meta-analysis 1996-2010. Sch Psychol Rev. 2012;41:387-412.

97. Albers L, Heinen F, Landgraf M, Straube A, Blum B, Filippopulos F, et al. Headache cessation by an educational intervention in grammar schools: a cluster randomized trial. Eur J Neurol. 2014:22(2):270-6.

98. Simpson RLPR, Smith CR. Critical educational program components for students with emotional and behavioral disorders: science, policy, and practice. Rem Spec Educ. 2011;32(3):230-42.

99. Rivera MO, Al-Otaiba S, Koorland MA. Reading instruction for students with emotional and behavioral disorders and at risk of antisocial behaviors in primary grades: review of literature. Behav Disord. 2006;31(3):323-37.

100. Araya R, Fritsch R, Spears M, Rojas G, Martinez V, Barroilhet S, et al. School intervention to improve mental health of students in Santiago, Chile a randomized clinical trial. Jama Pediatr. 2013;167(11):1004-10.

101. Tol WA, Komproe IH, Jordans MJ, Vallipuram A, Sipsma H, Sivayokan $S$, et al. Outcomes and moderators of a preventive school-based mental health intervention for children affected by war in Sri Lanka: a cluster randomized trial. World Psychiatr Off J World Psychiatr Assoc. 2012;11(2):114-22.
102. Tol WA, Komproe IH, Susanty D, Jordans MJ, Macy RD, De Jong JT. School-based mental health intervention for children affected by political violence in Indonesia: a cluster randomized trial. JAMA J Am Med Assoc. 2008;300(6):655-62.

103. Anderson LM, Shinn C, Fullilove MT, Scrimshaw SC, Fielding JE, Normand J, et al. The effectiveness of early childhood development programs. A systematic review. Am J Prevent Med. 2003;24(3 Suppl):32-46.

104. Nelson G, Westhues A, MacLeod J. A meta-analysis of longitudinal research on preschool prevention programs for children. Prevent Treat. 2003;6:31

105. Schweinhart $\sqcup$, Montie J, Xiang Z, Barnett WS, Belfield CR, Nores M. Lifetime effects: the High/Scope Perry Preschool study through age 40. 2005.

106. Aboud FE. Evaluation of an early childhood preschool program in rural Bangladesh. Early Child Res Q. 2006;21:46-60.

107. Cueto S, Guerrero G, Leon J, Zevallos A, Sugimaru C. Promoting early childhood development through a public programme: Wawa Wasi in Peru. Oxford: Oxford, UK Young Lives, Department of International Development; 2009.

108. Kagitcibasi C, Sunar D, Bekman S. Long-term effects of early intervention: turkish low-income mothers and children. J Appl Dev Psychol. 2001;22(4):333-61.

109. Kagitcibasi C, Sunar D, Bekman S, Baydar N, Cemalcilar Z. Continuing effects of early enrichment in adult life: the Turkish early enrichment project 22 years later. J Appl Dev Psychol. 2009;30(6):764-79.

110. Barlow J, Parsons J, Stewart-Brown S. Preventing emotional and behavioural problems: the effectiveness of parenting programmes with children less than 3 years of age. Child Care Health Dev. 2005;31(1):33-42.

111. Cooper PJ, Tomlinson M, Swartz L, Landman M, Molteno C, Stein A, et al. Improving quality of mother-infant relationship and infant attachment in socioeconomically deprived community in South Africa: randomised controlled trial. BMJ Br Med J. 2009;338:b974.

112. Jin X, Sun Y, Jiang F, Ma J, Morgan C, Shen X. "Care for development" intervention in rural China: a prospective follow-up study. J Dev Behav Pediatr JDBP. 2007;28(3):213-8.

113. Mejia A, Calam R, Sanders MR. A review of parenting programs in developing countries: opportunities and challenges for preventing emotional and behavioral difficulties in children. Clin Child Fam Psychol Rev. 2012;15(2):163-75.

114. Rahman A, lqbal Z, Roberts C, Husain N. Cluster randomized trial of a parent-based intervention to support early development of children in a low-income country. Child Care Health Dev. 2009;35(1):56-62.

115. Walker S, Chang SM. Effectiveness of parent support programmes in enhancing learning in the under-3 age group. Early Child Matt. 2013;120:45-9.

116. Wendland-Carro J, Piccinini CA, Millar WS. The role of an early intervention on enhancing the quality of mother-infant interaction. Child Dev. 1999;70(3):713-21.

117. Kaminski JW, Valle LA, Filene $\mathrm{JH}$, Boyle CL. A meta-analytic review of components associated with parent training program effectiveness. J Abnorm Child Psychol. 2008;36(4):567-89.

118. Fayyad JA, Farah L, Cassir Y, Salamoun MM, Karam EG. Dissemination of an evidence-based intervention to parents of children with behavioral problems in a developing country. Eur Child Adolesc Psychiatr. 2010;19(8):629-36.

119. Oveisi S, Ardabili HE, Dadds MR, Majdzadeh R, Mohammadkhani $P$, Rad JA, et al. Primary prevention of parent-child conflict and abuse in Iranian mothers: a randomized-controlled trial. Child Abuse Negl. 2010;34(3):206-13.

120. Vasquez M, Meza L, Almandarez O, Santos A, Matute RC, Canaca LD, Cruz A, Acosta S, Bacilla MAG, Wilson L, Azuero A, Tami I, Holcomb L, Saenz K. Evaluation of a strengthening families (Familias Fuertes) intervention for parents and adolescents in Honduras. South Online J Nurs Res. 2010;10(3):e1-25.

121. Balaji M, Andrews T, Andrew G, Patel V. The acceptability, feasibility, and effectiveness of a population-based intervention to promote youth health: an exploratory study in Goa, India. J Adoles Health. 2011;48(5):453-60.

122. Brady M, Assaad R, Ibrahim B, Salem A, Salem R. Providing new opportunities to adolescent girls in socially conservative settings: the Ishraq program in rural Upper Egypt. 2007. 
123. Jewkes R, Nduna M, Levin J, Jama N, Dunkle K, Puren A, et al. Impact of stepping stones on incidence of HIV and HSV-2 and sexual behaviour in rural South Africa: cluster randomised controlled trial. BMJ Br Med J. 2008;337:a506.

124. Kermode M, Herrman H, Arole R, White J, Premkumar R, Patel V. Empowerment of women and mental health promotion: a qualitative study in rural Maharashtra, India. BMC Publ Health. 2007;7(1):225.

125. Kim J, Ferrari G, Abramsky T, Watts C, Hargreaves J, Morison L, et al. Assessing the incremental effects of combining economic and health interventions: the IMAGE study in South Africa. Bull World Health Organ. 2009;87(11):824-32.

126. Pronyk PM, Hargreaves JR, Kim JC, Morison LA, Phetla G, Watts C, et al. Effect of a structural intervention for the prevention of intimate-partner violence and HIV in rural South Africa: a cluster randomised trial. Lancet. 2006;368(9551):1973-83.

127. Ssewamala FM, Han CK, Neilands TB. Asset ownership and health and mental health functioning among AIDS-orphaned adolescents: findings from a randomized clinical trial in rural Uganda. Soc Sci Med. 2009;69(2):191-8.

128. Lund C, De Silva M, Plagerson S, Cooper S, Chisholm D, Das J, et al. Poverty and mental disorders: breaking the cycle in low-income and middle-income countries. Lancet. 2011;378(9801):1502-14.

129. Stewart $R$, van Rooyen C, Dickson K, Majoro M, de Wet T. What is the impact of microfinance on poor people?: a systematic review of evidence from sub-Saharan Africa. 2010

130. Han HR, Park SY, Song H, Kim M, Kim KB, Lee HB. Feasibility and validity of dementia assessment by trained community health workers based on clinical dementia rating. J Am Geriatr Soc. 2013;61(7):1141-5.

131. Saito E, Nakamoto BK, Mendez MF, Mehta B, McMurtray A. Cost effective community based dementia screening: a Markov model simulation. Int J Alzheimer's Disease. 2014.

132. Jorm AF, Kitchener BA, O'Kearney R, Dear KB. Mental health first aid training of the public in a rural area: a cluster randomized trial [ISRCTN53887541]. BMC Psychiatr. 2004:4:33.

133. Chatterjee S, Naik S, John S, Dabholkar H, Balaji M, Koschorke M, et al. Effectiveness of a community-based intervention for people with schizophrenia and their caregivers in India (COPSI): a randomised controlled trial. Lancet. 2014;383(9926):1385-94.

134. Chatterjee S, Chowdhary N, Pednekar S, Cohen A, Andrew G, Andrew $G$, et al. Integrating evidence-based treatments for common mental disorders in routine primary care: feasibility and acceptability of the MANAS intervention in Goa, India. World Psychiatr Off J World Psychiatr Assoc. 2008;7(1):39-46.

135. Chatterjee S, Patel V, Chatterjee A, Weiss HA. Evaluation of a community-based rehabilitation model for chronic schizophrenia in rural India. Br J Psychiatr J Ment Sci. 2003;182:57-62.
136. Chatterjee S, Pillai A, Jain S, Cohen A, Patel V. Outcomes of people with psychotic disorders in a community-based rehabilitation programme in rural India. Br J Psychiatr J Ment Sci. 2009;195(5):433-9.

137. Agara AJ, Onibi OE. Effects of group psychoeducation (GPE) on compliance with scheduled clinic appointments in a neuro-psychiatric hospital in southwest Nigeria: a randomised control trial (RCT). Ann Acad Med Singapore. 2007;36(4):272-5.

138. Koolaee AK, Etemadi A. The outcome of family interventions for the mothers of schizophrenia patients in Iran. Int J Soc Psychiatr. 2010;56(6):634-46.

139. Kulhara P, Chakrabarti S, Avasthi A, Sharma A, Sharma S. Psychoeducational intervention for caregivers of Indian patients with schizophrenia: a randomised-controlled trial. Acta Psychiatr Scand. 2009;1 19(6):472-83.

140. Li Z, Arthur D. Family education for people with schizophrenia in Beijing, China: randomised controlled trial. Br J Psychiatr J Ment Sci. 2005;187:339-45

141. Ran MS, Xiang MZ, Chan CL, Leff J, Simpson P, Huang MS, et al. Effectiveness of psychoeducational intervention for rural Chinese families experiencing schizophrenia-a randomised controlled trial. Soc Psychiatr Psychiatr Epidemiol. 2003;38(2):69-75.

142. Sharif F, Shaygan M, Mani A. Effect of a psycho-educational intervention for family members on caregiver burdens and psychiatric symptoms in patients with schizophrenia in Shiraz, Iran. BMC Psychiatr. 2012;12:48.

143. Xia J, Merinder LB, Belgamwar MR. Psychoeducation for schizophrenia. The Cochrane database of systematic reviews. 2011 (6):CD002831. PubMed PMID: 21678337

144. Farooq S, Nazar Z, Irfan M, Akhter J, Gul E, Irfan U, et al. Schizophrenia medication adherence in a resource-poor setting: randomised controlled trial of supervised treatment in out-patients for schizophrenia (STOPS). Br J Psychiatr J Ment Sci. 2011;199(6):467-72.

145. Maneesakorn S, Robson D, Gournay K, Gray R. An RCT of adherence therapy for people with schizophrenia in Chiang Mai, Thailand. J Clin Nurs. 2007;16(7):1302-12.

146. Rahman A, Malik A, Sikander S, Roberts C, Creed F. Cognitive behaviour therapy-based intervention by community health workers for mothers with depression and their infants in rural Pakistan: a cluster-randomised controlled trial. Lancet. 2008;372(9642):902-9.

147. Dias A, Dewey ME, D'Souza J, Dhume R, Motghare DD, Shaji KS, et al. The effectiveness of a home care program for supporting caregivers of persons with dementia in developing countries: a randomised controlled trial from Goa, India. PLoS One. 2008;3(6):e2333.

\section{Submit your next manuscript to BioMed Central and we will help you at every step:}

- We accept pre-submission inquiries

- Our selector tool helps you to find the most relevant journal

- We provide round the clock customer support

- Convenient online submission

- Thorough peer review

- Inclusion in PubMed and all major indexing services

- Maximum visibility for your research

Submit your manuscript at www.biomedcentral.com/submit
() Biomed Central 